Case Report

\title{
A Case of Relapsing Polychondritis Initiating with Unexplained Fever
}

\author{
Kosuke Hirayama, ${ }^{1}$ Nozomi Iwanaga, ${ }^{1}$ Yasumori Izumi, ${ }^{1}$ Satoshi Yoshimura, ${ }^{1}$ \\ Kazuhiro Kurohama, ${ }^{2}$ Mai Yamashita, ${ }^{1}$ Taichi Takahata, ${ }^{3}$ Ryuta Oku, ${ }^{4}$ \\ Masahiro Ito, ${ }^{2}$ Atsushi Kawakami, ${ }^{5}$ and Kiyoshi Migita ${ }^{1}$ \\ ${ }^{1}$ Department of General Internal Medicine and Rheumatology, Nagasaki Medical Center, Kubara 2-1001-1, Omura 856-8562, Japan \\ ${ }^{2}$ Department of Pathology, Nagasaki Medical Center, Kubara 2-1001-1, Omura 856-8562, Japan \\ ${ }^{3}$ Department of Ophthalmology, Nagasaki Medical Center, Kubara 2-1001-1, Omura 856-8562, Japan \\ ${ }^{4}$ Department of Otolaryngology, Nagasaki Medical Center, Kubara 2-1001-1, Omura 856-8562, Japan \\ ${ }^{5}$ Department of Rheumatology, Nagasaki University Hospital, Sakamoto 1-7-1, Nagasaki 852-8501, Japan
}

Correspondence should be addressed to Kiyoshi Migita; migita@nagasaki-mc.com

Received 19 August 2015; Accepted 9 November 2015

Academic Editor: Thomas R. Chauncey

Copyright ( 2016 Kosuke Hirayama et al. This is an open access article distributed under the Creative Commons Attribution License, which permits unrestricted use, distribution, and reproduction in any medium, provided the original work is properly cited.

Relapsing polychondritis (RP) is a rare autoimmune disease affecting the multiple organ system. Here, we describe a case of RP initially presenting with high fever. The patient was referred to our hospital for further examination of fever of unknown origin (FUO). On admission, the patient reported dry cough in addition to fever. On physical examination, her red, swollen ears were noted, attributed on histology to inflammation with auricular perichondritis. She was diagnosed with RP and treated with oral prednisone (50 $\mathrm{mg} /$ day); her fever and auricular inflammation resolved. The patient no longer reported cough and body temperature returned to normal and the elevated levels of C-reactive protein (CRP) were normalized. In this case, identification of the origin of fever was a challenge because of unspecific symptoms; however, awareness of the systemic manifestations of RP may lead to the prompt diagnosis and therapeutic intervention.

\section{Introduction}

Relapsing polychondritis (RP) is a rare systemic autoimmune disease of unknown etiology that is characterized by recurrent inflammation of the cartilaginous and connective tissues [1]. The most commonly affected cartilages are those of the ears; however, multiple organ involvement, including the eyes, skin, musculoskeletal system, kidneys, cardiovascular system, and central nervous system, is not unusual [2]. Patients with RP typically present with unilateral or bilateral inflammation of the external aspects of the ears. Other frequently involved structures are the cartilaginous portions of the nose, the peripheral joints, and the tracheobronchial tree [3]. Clinically, involvement of the ears and nose is often the key to the diagnosis, because the distribution of the inflammation coincides with areas of cartilaginous tissue [4].
However, patients eventually diagnosed with RP may initially present with general, nonspecific symptoms, such as fever and malaise, which may delay the diagnosis [5]. Here, we describe a patient with RP whose initial manifestation was a high fever.

\section{Case Report}

A 58-year-old female was referred to our department in January 2014 with spiking fever $\left(>38.5^{\circ} \mathrm{C}\right)$ of 1-month duration. Examinations at local hospitals had not identified the cause of the fever and she had not responded to antibiotic therapy. At this stage, she was referred to our institution with a diagnosis of fever of unknown origin (FUO). Her history was unremarkable and she was not taking regular medications. On admission, the patient complained of chills. She had 

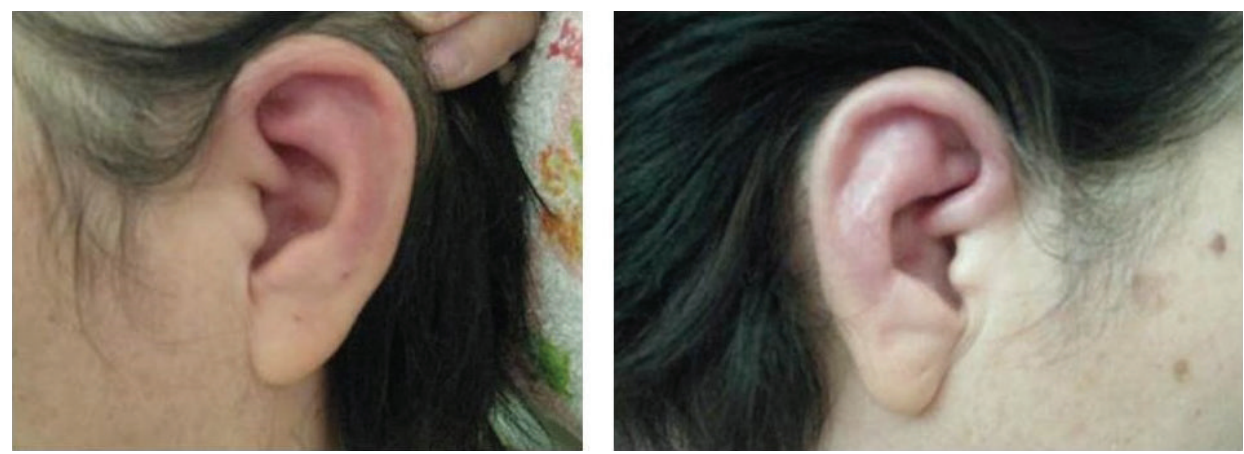

FIGURE 1: Inflammation of both ears. Obvious redness of the auricularis in this patient.

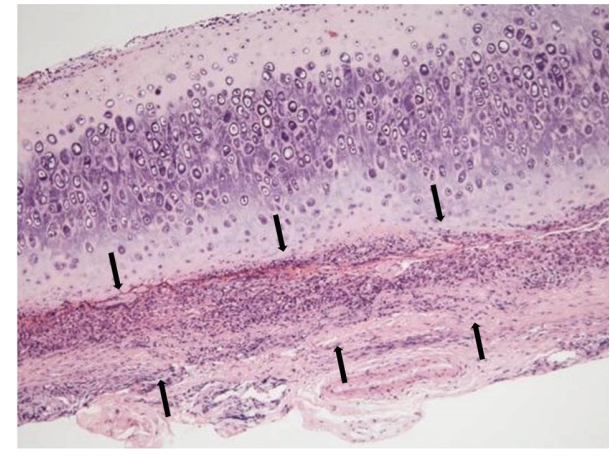

(a)

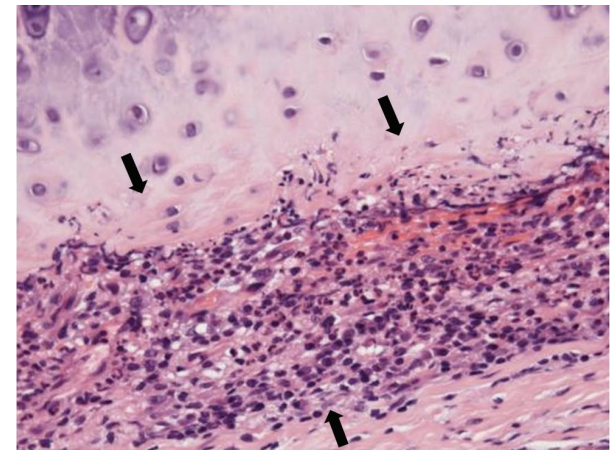

(b)

FIGURE 2: Histological findings of biopsy specimen from the left ear. Perichondritis with the mononuclear cells and polymorphonuclear leukocytes at the fibrochondral junction (hematoxylin and eosin, (a) original magnification $\times 50$, (b) original magnification $\times 200$ ). The arrows show perichondritis with the presence of mononuclear cells and polymorphonuclear leukocytes at the fibrochondral junction. Basophil's infiltration was not observed.

a high fever of up to $38.4^{\circ} \mathrm{C}$ as well as a nonproductive cough. Otological examination revealed tender and swollen pinnae (Figure 1) with characteristic sparing of the lobule. There was no abnormality of the nose or eyes.

Laboratory findings (Table 1) showed a hemoglobin level of $11.1 \mathrm{~g} / \mathrm{dL}$, a total leukocyte count of $10,700 / \mathrm{mm}^{3}$, and elevations of the erythrocyte sedimentation rate and Creactive protein level. Serology tests for antinuclear antibody and autoantibodies including anti-cyclic citrullinated peptide antibody, PR3-ANCA, and MPO-ANCA were all negative.

There was no tracheal cartilage tenderness, and chest computed tomography showed neither interstitial pneumonia nor tracheal stenosis. Neither aortic root dilatation nor aortic regurgitation was observed by echocardiography (data not shown). Although infection and hematological malignancies were excluded, redness of the bilateral auricularis suggested auricular perichondritis despite anti-type II collagen antibody negativity. Biopsy specimens were from the skin and the cartilage of the pinna for histopathological study. The histological evaluation showed cellular infiltrates of lymphocytes, neutrophils, and plasma cells, especially at the cartilage-skin interface, and a reduced number of chondrocytes in areas of cartilage destruction (Figure 2). Other clinical features of RP, such as nonerosive arthritis, ocular inflammation, and nasal chondritis, were not confirmed, whereas the patient fulfilled the McAdam-Damiani-Levine criteria for the diagnosis of RP $[6,7]$, according to the presence of one of McAdam's signs (auricular chondritis) with positive histological confirmation. Based on the presence of polyarthritis, the patient was diagnosed with RP. She was started on $50 \mathrm{mg}$ of prednisolone daily, which led to an improvement in her symptoms. Both the fever and the auricular swelling disappeared. Tapering of her prednisolone dose in combination with the addition of $6 \mathrm{mg}$ methotrexate weekly was recommended due to the suspicion of steroidrelated psychiatric symptoms. Three months following her discharge from the hospital stay of 45 days, her corticosteroids were reduced to $12.5 \mathrm{mg}$ daily and the methotrexate was increased to $8 \mathrm{mg}$ weekly. There was no subsequent flareup of RP.

\section{Discussion}

Relapsing polychondritis is a rare systemic disease characterized by recurrent, widespread chondritis of the auricular, nasal, and tracheal cartilages [1]. Additional clinical features include audiovestibular dysfunction, ocular inflammation, vasculitis, myocarditis, and nonerosive arthritis [8]. Although the cause remains unknown, the etiology is suspected to be an autoimmune reaction against type II collagen [9]. Established diagnostic criteria are the original McAdam's criteria, which include the presence of three or 
TABLE 1: Laboratory findings on admission.

\begin{tabular}{|c|c|}
\hline \multicolumn{2}{|l|}{ Peripheral blood } \\
\hline Red blood cells & $358 \times 10^{4} / \mu \mathrm{L}$ \\
\hline Hemoglobin & $11.1 \mathrm{~g} / \mathrm{dL}$ \\
\hline Hematocrit & $33.4 \%$ \\
\hline White blood cells & $10700 / \mu \mathrm{L}$ \\
\hline Neutrophil & $80.0 \%$ \\
\hline Monocyte & $5.0 \%$ \\
\hline Lymphocyte & $15.0 \%$ \\
\hline Platelet & $41.7 \times 10^{4} / \mu \mathrm{L}$ \\
\hline \multicolumn{2}{|l|}{ Blood chemistry } \\
\hline Total protein & $7.3 \mathrm{~g} / \mathrm{dL}$ \\
\hline Total bilirubin & $0.5 \mathrm{mg} / \mathrm{dL}$ \\
\hline Glutamic-oxaloacetic transaminase & $19 \mathrm{IU} / \mathrm{L}(7-33)$ \\
\hline Glutamic-pyruvic transaminase & $26 \mathrm{IU} / \mathrm{L}(5-30)$ \\
\hline Lactate dehydrogenase & 139 IU/L (119-229) \\
\hline Alkaline phosphatase & $545 \mathrm{IU} / \mathrm{L}(80-250)$ \\
\hline Gamma-glutamyl transpeptidase & $109 \mathrm{IU} / \mathrm{L}(5-55)$ \\
\hline Creatinine kinase & $24 \mathrm{IU} / \mathrm{L}(60-160)$ \\
\hline Total cholesterol & $201 \mathrm{mg} / \mathrm{dL}$ \\
\hline Blood urea nitrogen & $13.5 \mathrm{mg} / \mathrm{dL}$ \\
\hline Creatinine & $0.5 \mathrm{mg} / \mathrm{dL}$ \\
\hline Alb & $3.2 \mathrm{~g} / \mathrm{dL}$ \\
\hline $\mathrm{Na}$ & $138 \mathrm{mEq} / \mathrm{L}$ \\
\hline $\mathrm{K}$ & $3.9 \mathrm{mEq} / \mathrm{L}$ \\
\hline $\mathrm{Cl}$ & $101 \mathrm{mEq} / \mathrm{L}$ \\
\hline \multicolumn{2}{|l|}{ Serological tests } \\
\hline C-reactive protein & $11.64 \mathrm{mg} / \mathrm{dL}(<0.30)$ \\
\hline Erythrocyte sedimentation rate & $72.0 \mathrm{~mm} / \mathrm{hr}$ \\
\hline Ferritin & $548 \mathrm{ng} / \mathrm{mL}(<170)$ \\
\hline C3 & $161 \mathrm{mg} / \mathrm{dL}(86-160)$ \\
\hline $\mathrm{C} 4$ & 32 mg/dL (17-45) \\
\hline ANA & $(-)(<40)$ \\
\hline Anti-CCP Ab & $<0.6 \mathrm{U} / \mathrm{mL}(<4.5)$ \\
\hline MPO-ANCA & $<1.0 \mathrm{U} / \mathrm{mL}$ \\
\hline RR3-ANCA & $<1.0 \mathrm{U} / \mathrm{mL}$ \\
\hline Type II collagen Ab & 15.0 EU/mL $(<25.0)$ \\
\hline $\operatorname{IgG}$ & $1580 \mathrm{mg} / \mathrm{dL}(900-2000)$ \\
\hline MMP-3 & $65.1 \mathrm{ng} / \mathrm{mL}(<59.7)$ \\
\hline \multicolumn{2}{|l|}{ Microbiological test } \\
\hline HCV-Ab & $(-)$ \\
\hline HBsAg & $(-)$ \\
\hline CMV-antigenemia & $(-)$ \\
\hline Blood culture & $(-)$ \\
\hline$\beta$-D-Glucan & $<3.4 \mathrm{pg} / \mathrm{mL}$ \\
\hline Urinalysis & Normal \\
\hline
\end{tabular}

ANA: antinuclear antibody, ANCA: antineutrophil cytoplasmic antibody, CMV: cytomegalovirus, HBsAg: hepatitis B surface antigen, HCV: hepatitis $\mathrm{C}$ virus, MMP-3: matrix metalloproteinase-3, MPO: myeloperoxidase, RF: rheumatoid factor, and RR3: proteinase 3 .

more of the following clinical features: bilateral auricular chondritis; nonerosive, seronegative inflammatory polyarthritis; nasal chondritis; ocular inflammation; respiratory tract chondritis; and cochlear and/or vestibular dysfunction [6].

A striking symptom in our patient was the spiking fever. Although there are no specific laboratory findings in RP, such as positivity for anti-type II collagen antibody, our patient fulfilled one of the McAdam criteria in addition to the typical histological findings. Patients with RP may present with various signs and symptoms that are often misdiagnosed. Among patients who present with general, unspecific signs, such as fever and progressive malaise, diagnosis and treatment may be significantly delayed [10]. The most common signs of RP are auricular inflammation (89\%), nonerosive arthritis (72\%), nasal chondritis (11\%), and laryngotracheal disease (55\%) [11]. Fever is a nonspecific sign that occurs in a wide array of disorders and its origin can be extremely difficult to determine [2]. Patients who present with RP-related fever that is not diagnosed as such may receive a diagnosis of FUO [12]. However, RP has a chronic relapsing course that can be life-threatening if there is airway involvement, and laryngotracheal involvement is a major cause of morbidity and mortality $[13,14]$. Therefore, in patients whose only symptoms are prolonged fever and cough, with no pulmonary abnormalities on CT, the differential diagnosis should include RP to improve the likelihood of a timely therapeutic intervention to prevent disease progression.

Fever is often caused by the release of endogenous inflammatory cytokines in response to tissue inflammation [15]. An autoimmune reaction against type II collagen stimulates inflammatory cells, especially cytokine-producing macrophages. Glucocorticoid therapy is a fundamental component in the treatment of RP and its long-term use is recommended for most of these patients [11]. If significant organ involvement is proven, high-dose corticosteroids are often necessary. Severe disease may require treatment with immunosuppressive agents. In patients intolerant or, rarely, unresponsive to steroid therapy or in whom steroid-sparing therapy is required, immunosuppressants such as methotrexate, azathioprine, and cyclosporine play a role, particularly when there is severe respiratory or vascular involvement $[16,17]$. Airway involvement by RP is considered to be a common course of morbidity and mortality [13], whereas it was reported that laryngotracheal involvement was seen less frequently in an Asian population [18]. Our patient was successfully treated with glucocorticoid and methotrexate, which were selected for their steroid-tapering effects. Associations with autoinflammatory disorders, such as familial Mediterranean fever (FMF), were reported in RP $[19,20]$. In the present case, there was no relapsing periodic fever and sustained high fever was completely cured by steroid therapy; therefore, overlapping FMF in RP seems to be unlikely.

In summary, we presented the case with unexplained fever that was later determined to be an early manifestation of RP. FUO may be one of the various and nonspecific presenting features of RP. Physicians should therefore be aware of the various systemic manifestations of this disease to enable its prompt treatment. 


\section{Conflict of Interests}

The authors declare that they have no competing interests.

\section{References}

[1] D. E. Trentham and C. H. Le, "Relapsing polychondritis," Annals of Internal Medicine, vol. 129, no. 2, pp. 114-122, 1998.

[2] J. F. Molina and L. R. Espinoza, "Relapsing polychondritis," Bailliere's Best Practice and Research in Clinical Rheumatology, vol. 14, no. 1, pp. 97-109, 2000.

[3] R. Chopra, N. Chaudhary, and J. Kay, "Relapsing polychondritis," Rheumatic Disease Clinics of North America, vol. 39, no. 2, pp. 263-276, 2013.

[4] T. Lahmer, M. Treiber, A. von Werder et al., "Relapsing polychondritis: an autoimmune disease with many faces," Autoimmunity Reviews, vol. 9, no. 8, pp. 540-546, 2010.

[5] L. Cantarini, A. Vitale, M. G. Brizi et al., "Diagnosis and classification of relapsing polychondritis," Journal of Autoimmunity, vol. 48-49, pp. 53-59, 2014.

[6] L. P. McAdam, M. A. O’Hanlan, R. Bluestone, and C. M. Pearson, "Relapsing polychondritis: prospective study of 23 patients and a review of the literature," Medicine, vol. 55, no. 3 , pp. 193-215, 1976.

[7] J. M. Damiani and H. L. Levine, "Relapsing polychondritisreport of ten cases," Laryngoscope, vol. 89, no. 6, part 1, pp. 929946, 1979.

[8] A. Sharma, K. Gnanapandithan, K. Sharma, and S. Sharma, "Relapsing polychondritis: a review," Clinical Rheumatology, vol. 32, no. 11, pp. 1575-1583, 2013.

[9] J. M. Foidart, S. Abe, G. R. Martin et al., "Antibodies to type II collagen in relapsing polychondritis," The New England Journal of Medicine, vol. 299, no. 22, pp. 1203-1207, 1978.

[10] E. Letko, P. Zafirakis, S. Baltatzis, A. Voudouri, C. Livir-Rallatos, and C. S. Foster, "Relapsing polychondritis: a clinical review," Seminars in Arthritis and Rheumatism, vol. 31, no. 6, pp. 384395, 2002.

[11] P. D. Kent, C. J. Michet Jr., and H. S. Luthra, "Relapsing polychondritis," Current Opinion in Rheumatology, vol. 16, no. 1, pp. 56-61, 2004.

[12] J. N. Avila, S. B. Carvalho, G. Tavares, and R. Garcia, "Fever of unknown origin in a patient with red ears: relapsing polychondritis," BMJ Case Reports, 2014.

[13] A. Ernst, S. Rafeq, P. Boiselle et al., "Relapsing polychondritis and airway involvement," Chest, vol. 135, no. 4, pp. 1024-1030, 2009.

[14] C. J. Michet Jr., C. H. McKenna, H. S. Luthra, and W. M. O'Fallon, "Relapsing polychondritis. Survival and predictive role of early disease manifestations," Annals of Internal Medicine, vol. 104, no. 1, pp. 74-78, 1986.

[15] L. Arnaud, A. Mathian, J. Haroche, G. Gorochov, and Z. Amoura, "Pathogenesis of relapsing polychondritis: a 2013 update," Autoimmunity Reviews, vol. 13, no. 2, pp. 90-95, 2014.

[16] K. Yamaoka, K. Saito, K. Hanami et al., "A case of lifethreatening refractory polychondritis successfully treated with combined intensive immunosuppressive therapy with methotrexate," Modern Rheumatology, vol. 17, no. 2, pp. 144-147, 2007.

[17] J. Park, K. M. Gowin, and H. R. Schumacher Jr., "Steroid sparing effect of methotrexate in relapsing polychondritis," Journal of Rheumatology, vol. 23, no. 5, pp. 937-938, 1996.
[18] A. Sharma, P. Bambery, A. Wanchu et al., "Relapsing polychondritis in North India: a report of 10 patients," Scandinavian Journal of Rheumatology, vol. 36, no. 6, pp. 462-465, 2007.

[19] A. Salihoglu, E. Seyahi, S. Celik, and S. Yurdakul, "Relapsing polychondritis in a patient with familial Mediterranean fever and amyloidosis," Clinical and Experimental Rheumatology, vol. 26, no. 4, supplement 50, p. S125, 2008.

[20] E. B. Miller, J. A. Friedman, Y. Lahav, and Z. Landau, "Relapsing polychondritis and familial Mediterranean fever-an association," Clinical Rheumatology, vol. 30, no. 5, pp. 711-713, 2011. 


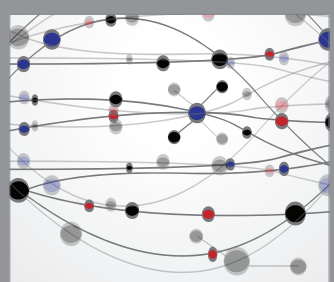

The Scientific World Journal
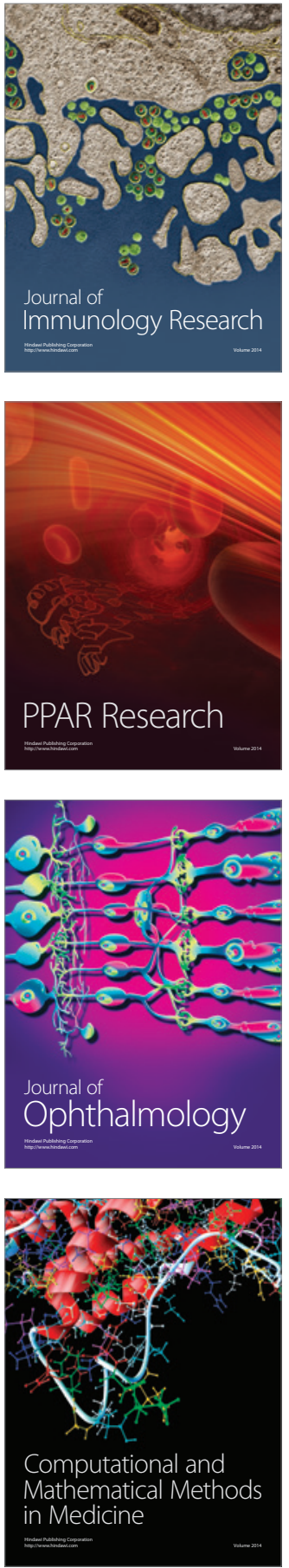

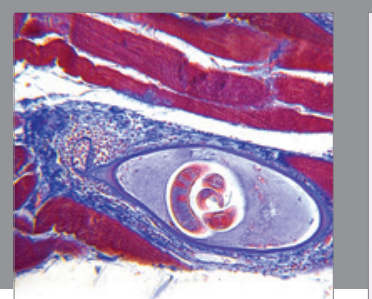

Gastroenterology Research and Practice

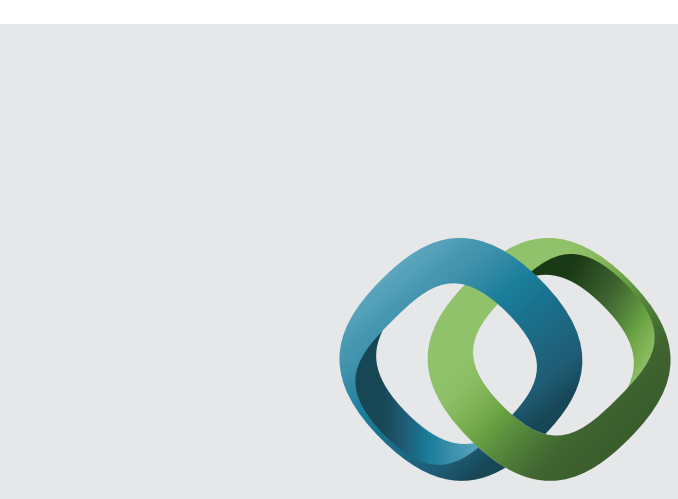

\section{Hindawi}

Submit your manuscripts at

http://www.hindawi.com
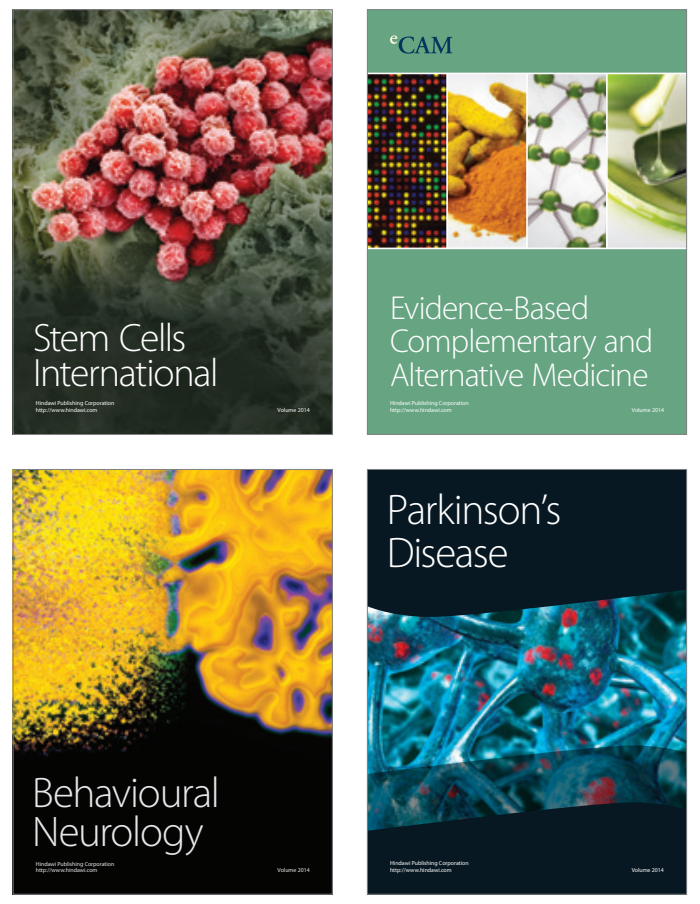
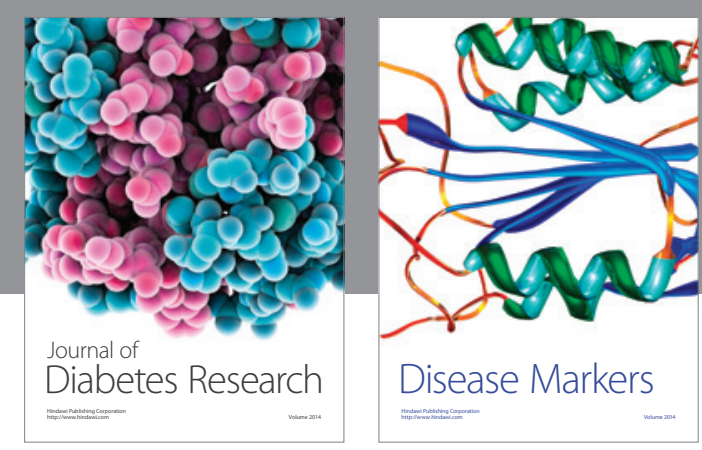

Disease Markers
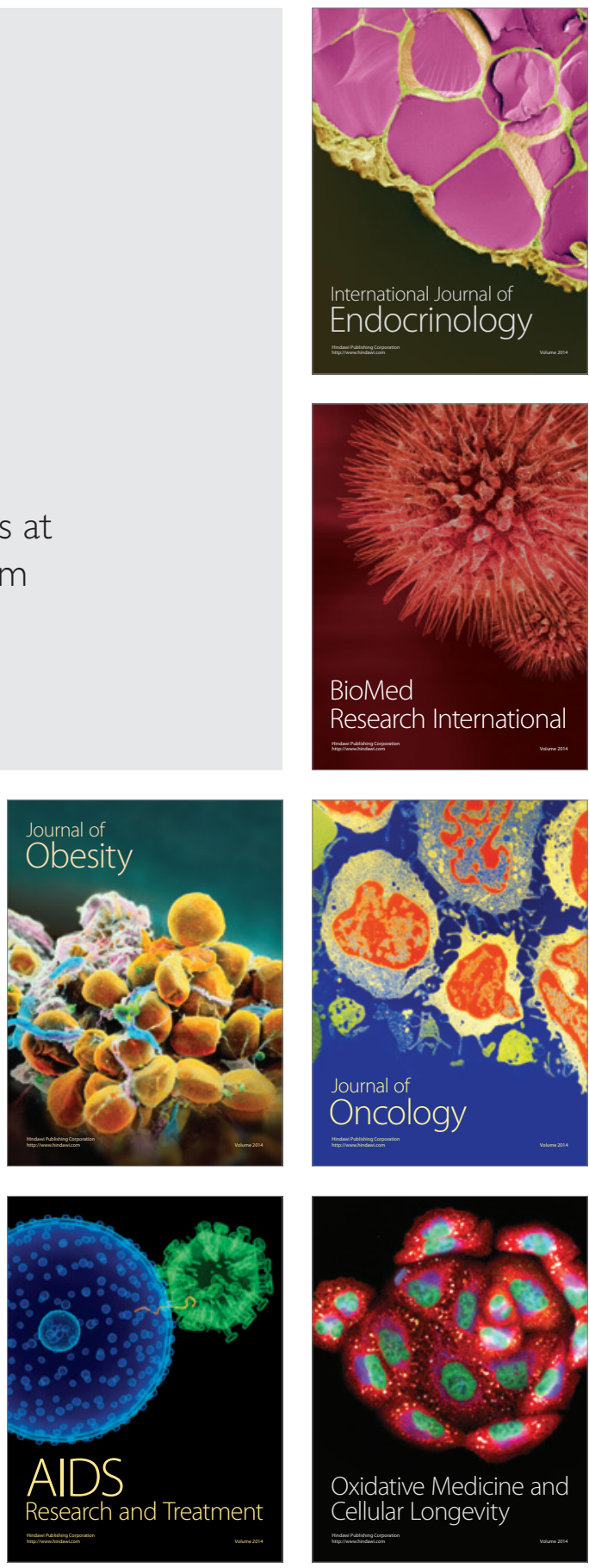